\title{
A TECNOLOGIA DA INFORMAÇÃO COMO SUPORTE AO AJUSTE DA PREVISÃO DA DEMANDA: UM ESTTUDO DE CASO EM UMA EMPRESA DE BEBIDAS CARBONATADAS
}

\section{THE INFORMATION TECHNOLOGY AS SUPPORT TO THE ADJUSTMENT OF DEMAND FORECAST: A CASE STUDY IN A CARBONATED BEVERAGES' COM- PANY}

\author{
Alexandre Pereira Salgado Junior* asalgado@usp.br \\ Mayara Segatto* mayarasegatto@gmail.com \\ Rogério Cerávolo Calia* calia@usp.br \\ Jocimar A. Fiorotto jocimar.antonio1477@terra.com.br \\ Luciana T. Berton Iberton32@yahoo.com.br \\ *Universidade de São Paulo
}

\begin{abstract}
Resumo: A gestão da cadeia de suprimentos é um problema que sempre instigou gestores por todo o mundo, ademais os modelos de previsão da demanda tradicionais não mais satisfazem os novos desafios da gestão dos estoques e da ruptura. Sendo assim, novas soluções foram desenvolvidas, buscando-se melhorar os níveis de serviço prestados ao consumidor final. Dentre elas, destaca-se a utilização da TI que, por disponibilizar a informação em tempo real, pode contribuir para o ajuste dos modelos tradicionais de previsão da demanda. Desta forma, o objetivo desta pesquisa é analisar como a TI pode ajudar o segmento de bebidas a ajustar sua previsão de demanda. O método de pesquisa utilizado foi o estudo de caso, analisando, por conveniência, uma empresa de bebidas carbonatadas. Para avaliação dos dados, utilizou-se a técnica de análise de conteúdo. Como principais resultados, destacam-se melhorias no nível dos estoques, na ruptura e no nível de serviço.
\end{abstract}

Palavras-chave: Previsão da demanda. Informação em tempo real. Bebidas carbonatadas. Tecnologia da informação. Nível de serviço.

Abstract: The supply chain management is a problem that always instigated managers around the world, besides that the traditional models of demand forecast no longer meet the challenges of managing the stocks and the collapse. Therefore, new solutions were developed, aiming to improve the service levels provided to the final consumer. Among them, there is the use of IT that, by providing the information in real time, can contribute to the adjustment of traditional models of demand forecast. Thus, this research aims to analyze how IT can help the segment of beverages as a support for the adjustment. The research method used was the case study, analyzing, for convenience, a carbonated drinks' company. For data analysis, it was used the technique of content analysis. The main results include improvements in the stocks' level, at collapse and service's level.

Key-Words: Demand forecast. Real time information. Carbonated beverages. Information technology. Service level. 


\section{INTRODUÇÃO}

As transformações pelas quais a sociedade vem passando, principalmente nas últimas duas décadas, em razão do impacto da chamada nova economia da informação, têm estabelecido um cenário extremamente competitivo, encarado por todas as organizações, grandes ou pequenas, privadas ou não.

Para Kearns e Sabherwal (2007), a nova realidade mundial depende, cada vez mais, da Tecnologia da Informação (TI) como recurso estratégico para a obtenção de vantagem competitiva. De acordo com Porter (1996), o que se vê é a intensificação da adoção da Tl como suporte aos negócios, que se inicia com a concepção de um produto/serviço, passando pela sua comercialização, produção e chegando à logística de sua distribuição.

Segundo Goles, Hawk e Kaiser (2008), com o desenvolvimento dos sistemas de informação, surgiram os sistemas de integração ERP (Enterprise Resource Planning), prometendo a gestão sistêmica das empresas. No entanto, mesmo possibilitando um ajuste nos estoques, principalmente em função da otimização dos processos internos e da redução do lead time, esse sistema não proporcionou contribuição significativa para que o SCM (Supply Chain Management) atingisse o nível almejado pelas empresas mais competitivas. Isso se deve ao fato do ERP, que se originou da evolução dos sistemas MRP (Material Requirement Planning) e MRPII (Manufacturing Resource Planning), se restringir à análise interna da empresa. Para se atingir o nível de serviço almejado pelas empresas mais competitivas, é fundamental o estudo da oferta e demanda de mercado, fato este, limitante para o sistema ERP (FERNANDES, 2001; SILVA NETO, 2002; CORRÊA; GIANESI; CAON, 2001; SOUZA; SACCOL, 2003).

Dessa forma, a partir da década de 90, o foco passou a ser o das relações externas à empresa (FREITAS, 2001). Naquele momento, todos os esforços foram direcionados ao estudo das relações da empresa com seus stakeholders, em especial, com os atores da cadeia produtiva (SOROOR; TAROKH; SHEMSHADI, 2009).

Sendo assim, a implementação de sistemas para a integração da informação em tempo real, ao longo da cadeia, vem crescendo em função da necessidade do 
próprio mercado. A TI tem sido considerada um importante agente para a integração da cadeia de suprimentos (ou parte dela), em vários segmentos de negócios, inclusive auxiliando no ajuste da previsão de demanda. Para Wang (2008), ela pode auxiliar as empresas na obtenção de visibilidade global através da sua rede extensa de parceiros de negócios e ajudá-las a responder rapidamente a uma série de variáveis, da demanda dos clientes à falta de recursos.

O estudo da previsão da demanda não é algo novo. Ele tem sido realizado por vários setores e baseia-se em métodos qualitativos, como os relacionados à experiência dos vendedores, e quantitativos, como os baseados em análises estatísticas em séries temporais (CHEN; XIAO, 2009).

Entretanto, com o aumento do número de produtos, fornecedores e pontos de vendas, os modelos tradicionais de previsão da demanda tornaram-se ineficientes para as empresas mais competitivas. Isso se deve ao intervalo entre as previsões. Com um mercado turbulento e em constante mudança, é necessário um ajuste, em tempo real, desta previsão para reduzir as incertezas e, consequentemente, a falta e o excesso de produtos.

Todos esses fatores têm impacto direto na melhoria do nível de serviço prestado ao consumidor final. Este é o caso do segmento de bebidas carbonatadas no Brasil. Nesse contexto, a presente pesquisa tem como objetivo analisar como a TI pode ajudar o segmento de bebidas a ajustar seu modelo tradicional de previsão de vendas.

\section{REFERENCIAL TEÓRICO}

\subsection{Supply Chain Management (SCM) e a Tecnologia da Informação (TI)}

A gestão do nível de serviço prestado ao consumidor final da cadeia tornouse um fator determinante para o sucesso de qualquer empreendimento à medida que o grau de competitividade aumenta globalmente. Segundo Kaynak e Hartley (2008), SCM consiste em práticas internas, contidas na empresa, e práticas externas, que atravessam as fronteiras organizacionais para integrar uma empresa com 
seus clientes e fornecedores. Sendo assim, é necessário que a cadeia gerencie da melhor forma possível seus recursos, sua logística, seus estoques e suas informações, que deveriam ser disponibilizadas pelos sistemas em tempo real (GUNASEKARAN; NGAI, 2009).

O estoque existe como forma de se compensar as possíveis incapacidades de se gerenciar os elos da cadeia produtiva. Todavia, somente faz-se necessário quando há uma incerteza entre fornecimento e demanda, visto que, existindo uma sincronia entre os elos da cadeia produtiva, segundo Ballou (2001), a manutenção dos estoques torna-se desnecessária.

A gestão da demanda engloba o gerenciamento da carteira de pedidos e da previsão de vendas. A carteira de pedidos envolve a previsão da demanda mais simplificada, uma vez que é composta por pedidos confirmados de clientes. Já no sistema de produção para estoque, de maior complexidade, o planejador tem que recorrer às metodologias clássicas de previsão. A combinação de pedidos colocados e pedidos previstos é utilizada para representar a demanda em muitas empresas (SLACK et al., 2002).

No estudo, o problema está relacionado à parcela da demanda total, denominada previsão, que deve ser reestruturada de forma a melhorar o nível de serviços prestados ao consumidor final. Ou seja, é necessária uma melhor sincronização dos elos da cadeia produtiva e a realização de previsões mais precisas - que poderá ser atingido em função da disponibilidade da informação em tempo real por meio da TI.

Conforme Yan e Ghose (2010), para mercados mais voláteis, a avaliação do consumidor quanto ao produto é maior, e a concorrência é mais intensa, tornando a precisão das previsões muito mais valiosa para o varejo tradicional. Assim, a partir da perspectiva de rentabilidade, o varejo tradicional deve utilizar ativamente todos os meios operacionais disponíveis para melhorar a precisão das previsões.

O e-SCM destaca-se como uma ferramenta no auxílio à tomada de decisão ao longo da cadeia produtiva. De acordo com Souza e Saccol (2003), uma limitação significativa do sistema ERP é que ele se restringe à gestão da informação dentro da empresa. Já o e-SCM permite que a empresa acompanhe os negócios em toda a 
cadeia produtiva, desde os fornecedores iniciais até os clientes finais, todos interligados por meio da TI, adequando os níveis de serviço. Essa tecnologia está auxiliando as cadeias na adequação dos níveis de serviço (HENDRICKS; SINGHAL; STRATMAN, 2007).

Isso ocorre porque a informação da venda para o consumidor final está disponibilizada, em tempo real, para todos os elos da cadeia. Para Bose, Raktim e Alex (2008), a integração permite que a empresa se adapte às mudanças do ambiente mais rapidamente. Dessa forma, os fornecedores podem alterar seu ritmo de produção para acompanhar qualquer comportamento inesperado da demanda evitando o estoque e a ruptura. Segundo Soroor et al. (2009), os processos de coordenação nos quais os membros das cadeias estão envolvidos, têm aumentado em complexidade nos anos recentes e têm se tornado mais intensivos em informação.

Dado que os mercados estão sempre expostos à incerteza da demanda resultante da evolução econômica e de mudanças contínuas nas preferências dos consumidores, a informação é cada vez mais importante para os varejistas. Assim, a partilha de informação entre participantes da cadeia ajuda na troca de informações de previsão e alocação mais eficiente dos recursos financeiros, contribuindo para que os atores da cadeia considerem a melhoria dos sistemas de informação de mercado (YAN, 2010).

Conforme Koh e Gunasekaran (2008, p. 253), "no e-SCM os recursos são mais bem controlados e a tomada de decisão e o planejamento são realçados não somente por causa das vantagens intrínsecas do ERP, mas também porque os recursos da cadeia inteira estão agora disponíveis".

O mesmo acontece com todos os níveis de fornecimento. De acordo com Chang et al. (2008, p. 1809), "ao aplicar e-SCM, os pedidos podem ser previstos eficiente e corretamente, os custos em estoque, para os membros da cadeia de suprimentos, podem ser reduzidos, e a programação da produção pode ser ajustada para otimizar o tempo". 


\subsection{Previsão da Demanda}

As previsões da demanda são a base para o processo de planejamento, sendo uma das atividades mais importantes dentro de um sistema de produção. Todo o início de estudo de estoques está baseado em previsões de consumo de material. As previsões estabelecem estimativas futuras dos produtos acabados comercializados pelas empresas, e ainda definem quais, quantos e quando determinados produtos serão comprados pelos clientes.

Segundo Christopher (1997), a previsão pode ser baseada em modelos estatísticos, matemáticos ou econométricos ou, ainda, em modelos subjetivos apoiados em uma metodologia de trabalho clara e previamente definida. Entretanto, segundo Bayraktar et al. (2008, p. 195), "previsões de demanda, na prática, raramente são precisas e ficam ainda piores nos níveis mais complexos da cadeia de suprimentos". Ressalta, assim, Arnold (1999, p. 235) que "as previsões são mais precisas para períodos curtos. O futuro próximo impõe menos incertezas que o futuro distante”.

Vastas são as técnicas e modelos (estatísticos, operacionais e estratégicos) encontrados em literatura, como, por exemplo, aqueles em séries temporais, que analisam minuciosamente formas para se prever a demanda. Apesar da evolução desses métodos, a previsão de demanda não é uma ciência puramente exata. Ela envolve experiência e julgamento pessoal do planejador. No entanto, mesmo com todos os recursos disponíveis para se realizar uma boa previsão, se comparada com a carteira de pedidos, a parcela das vendas que deve ser prevista é muito difícil de ser gerenciada, sendo responsável pela existência da maior parte dos estoques.

Para Corrêa e Gianesi (1996, p. 234), "as incertezas de previsões e os erros correspondentes provêm de duas formas distintas: a primeira delas corresponde ao próprio mercado, de baixa previsibilidade; a segunda corresponde ao sistema de previsão". Outro problema é que o constante crescimento da oscilação da demanda de um número cada vez maior de produtos aumenta, na mesma proporção, a necessidade por reprogramação da produção. 
Dessa forma, um dos mecanismos para adequação dos estoques seria aquele que conseguisse melhorar as previsões ou transformá-las em carteira de pedidos, proporcionando uma maior sincronização entre a oferta e a demanda. Muitas empresas têm buscado transformar grande parte de sua previsão em carteira de pedidos, por meio do aumento do número de visitas técnicas ou oferecendo descontos para aqueles clientes que comprarem antecipadamente. Entretanto, existem segmentos nos quais esse procedimento não é possível. Sendo assim, estas empresas utilizam previsões para antecipar a demanda e planejar o quê, quanto e quando produzir (CHING, 1999).

Na prática, podem ocorrer combinações dos diversos modelos de evolução de consumo. Segundo Arnold (1999), há duas maneiras de se estimar o consumo: após a entrada do pedido, que é possível nos casos de prazo de fornecimento suficientemente longo; e através de métodos estatísticos, que são os mais utilizados.

Os métodos estatísticos calculam as previsões através de valores históricos. Dentre estes modelos destacam-se: método do último período, método da média móvel, método da média móvel ponderada, método da média com ponderação exponencial e método dos mínimos quadrados.

Yelland (2010) atesta as dificuldades de previsão para operações que utilizam modelos estatísticos. Em seu estudo, foi verificado que tais abordagens são frequentemente bloqueadas por qualquer falta de dados históricos ou de informações de tendência adequadas.

Sendo assim, a análise da integração da cadeia de suprimentos, com o objetivo de encontrar soluções que contribuam para a redução do grau de incerteza, colaborar para a melhoria das previsões de venda, da confiabilidade da entrega dos fornecedores e da gestão do lead time dos processos de fabricação. Isso é de fundamental importância para que as empresas possam diminuir as incertezas em relação aos ambientes interno e externo e, consequentemente, adequar seu nível de estoque, melhorar seu nível de serviço e reduzir a ruptura. Desta forma, novas soluções têm sido desenvolvidas e aplicadas nos mais diversos segmentos, buscandose melhorar ainda mais os níveis de serviço prestados ao consumidor final. 


\subsection{0 segmento de bebidas carbonatadas}

A indústria de bebidas carbonatadas consiste de organizações que produzem, comercializam, embalam, vendem e entregam bebidas carbonatadas aos consumidores. De acordo com Ferreira et al. (2009), o setor apresenta muitas pequenas empresas locais, embora pelo menos três grandes produtores mantenham o mais alto grau de reconhecimento de marca internacional.

Bebidas carbonatadas são populares em muitos mercados e são consumidas por uma variedade de grupos sociais e econômicos, embora o consumo per capita seja maior em alguns mercados. Segundo Ferreira et al. (2009, p. 697), "o Brasil é um dos maiores produtores de refrigerantes carbonatados, com mais de 800 fábricas, e um mercado consumidor de mais de 13 bilhões de litros por ano, que é o terceiro no mundo".

Nesse contexto, o estudo neste segmento justifica-se pela relevância do mercado consumidor e pela significativa produção de bebidas carbonatadas no Brasil.

\section{METODOLOGIA}

Devido à fase de desenvolvimento, na qual se apresentam os estudos acerca dos impactos da TI, no ajuste à previsão de demanda, existe uma deficiência na estruturação do conhecimento. Ela está relacionada à dificuldade de mensuração de indicadores quantitativos, uma vez que os benefícios e desvantagens gerados podem aparecer somente a longo prazo e indiretamente, o que gera problemas no levantamento de dados que poderiam ser tratados estatisticamente. Sendo assim, esta pesquisa deu-se de forma qualitativa e de natureza exploratória. Para Malhotra (2001), a pesquisa qualitativa exploratória proporciona uma melhor visão e compreensão do contexto do problema. Ressalta Mattar (2005) que, embora existam restrições a esse tipo de estudo, os estudos exploratórios mostram-se adequados quando a massa crítica de conhecimentos sobre um assunto não é extensa e importante, ao se constituírem etapas iniciais para a realização de estudos mais estruturados como os causais e descritivos. 
O método utilizado foi o estudo de caso, que permite uma investigação de características mais significativas e holísticas. Segundo Yin (2005), o estudo de caso é a estratégia preferida quando as questões são colocadas sob a forma de "como" ou "por que", que é o caso presente. Ainda segundo o autor, seis fontes de evidências devem ser utilizadas, na medida do possível, para que se obtenha um bom estudo de caso, a saber: (1) documentação; (2) registro em arquivos; (3) entrevistas; (4) observações diretas; (5) observações participantes; (6) artefatos físicos.

\subsection{Protocolo do Estudo de Caso}

De acordo com Yin (2005), os protocolos de pesquisa definem procedimentos padronizados para o estudo de caso poder ser reaplicado, em um mesmo estudo, por outros pesquisadores de modo a se obter os mesmos resultados. Sendo assim, os protocolos viabilizam a reprodutibilidade da pesquisa.

O protocolo de estudo de caso deve definir a questão da pesquisa, a hipótese a ser validada, as fontes de informação e as questões a serem respondidas. Note-se que as questões levantadas no protocolo de estudo de caso não são direcionadas às pessoas entrevistadas pelo pesquisador, mas são questões direcionadas ao próprio pesquisador, para guiá-lo de modo a obter o conjunto de evidências necessárias e suficientes para se responder às questões do protocolo (YIN, 2005).

Deste modo, o protocolo do estudo de caso, conforme sintetizado no quadro 1, visa analisar a implementação da Tecnologia de Informação como suporte ao ajuste semanal na previsão da demanda na empresa analisada. Para isso, foram entrevistados:

- Analista de Planejamento Pleno;

- Coordenador de Distribuição.

Além das entrevistas, também foram utilizados dados de séries temporais para avaliar a eficácia da TI como suporte ao ajuste na previsão da demanda.

Para estabelecer as relações causais entre o processo de ajuste na previsão da demanda e desempenho logístico, foram utilizados dados da própria empresa, 
adaptando os modelos clássicos de previsão da demanda por séries temporais em oposição aos ajustes em tempo real da informação por meio da TI.

Durante o estudo de caso, foi analisado o processo de ajuste semanal na previsão da demanda e as respectivas contribuições das organizações e departamentos envolvidos.

Protocolo do Estudo de Caso da Utilização da TI como Suporte ao Ajuste da Previsão da Demanda em uma Empresa de Bebidas

\begin{tabular}{|c|c|}
\hline Questão do estudo & $\begin{array}{l}\text { Qual e o Impacto Jo aluste semanal na phevlsgo da demanda ro desempenfo logist co de uma distribuldora de } \\
\text { ofbidas? }\end{array}$ \\
\hline Hipótese & 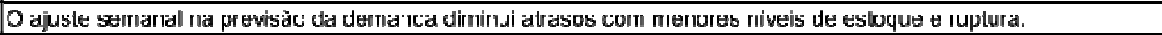 \\
\hline Unidade de Análise & O processo de ajuste a previsso da denenda de bebdas. \\
\hline Limites de Tempo & Je 2002 e 2009 \\
\hline Local & 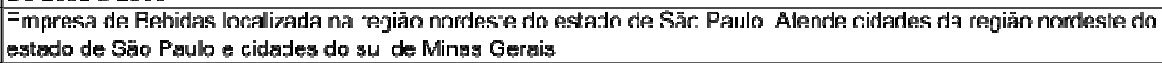 \\
\hline Validade dos construtos & dados de aravisf̃o a eperaçñes da prófria empresa \\
\hline $\begin{array}{l}\text { Validade Interna (qualidadc da } \\
\text { relaçảo causal) }\end{array}$ & nfomaçāo arn :empo real versus previsäo da demanda por séries temporais \\
\hline \multirow{4}{*}{ Questōes do estudo de caso } & Somo fol catruturado o grooesso de ej uate a grevisto ca demenda de bebidas? \\
\hline & $\begin{array}{l}\text { Quats sao as con lribuiçoes das orgarizaçoes e departarrentos envolvidos no processo de ajuste à previsao da } \\
\text { demanda de begidas? }\end{array}$ \\
\hline & $\begin{array}{l}\text { Quais sāo os nopactos do frccesso de ajuste à previsāo da de nanda de bebicis nu nivel de serviço e na reduçāu } \\
\text { de estbqua? }\end{array}$ \\
\hline & Quais sắo as oportınidades ce melhoria no prccesso de ajuste à previsão da denarda de bebicas? \\
\hline
\end{tabular}

Quadro 1 - Protocolo do Estudo de Caso

Fonte: Adaptado de Yin (2005).

\subsection{Escolha do Caso}

A empresa em estudo faz parte da cadeia de suprimentos do segmento de bebidas, envolvendo varejo, centro de distribuição, indústria e fornecedores de insumos básicos. Ela detém mais de $60 \%$ das vendas do setor na região, tendo sido escolhida conforme sua relevância devido à representatividade no segmento e conveniência em termos de localização. Optou-se pela análise de um único caso, com uma distribuição geográfica abrangente, cujo fenômeno é muito recente no país. A figura 1 representa a parte da cadeia de suprimentos em análise no estudo de caso. 

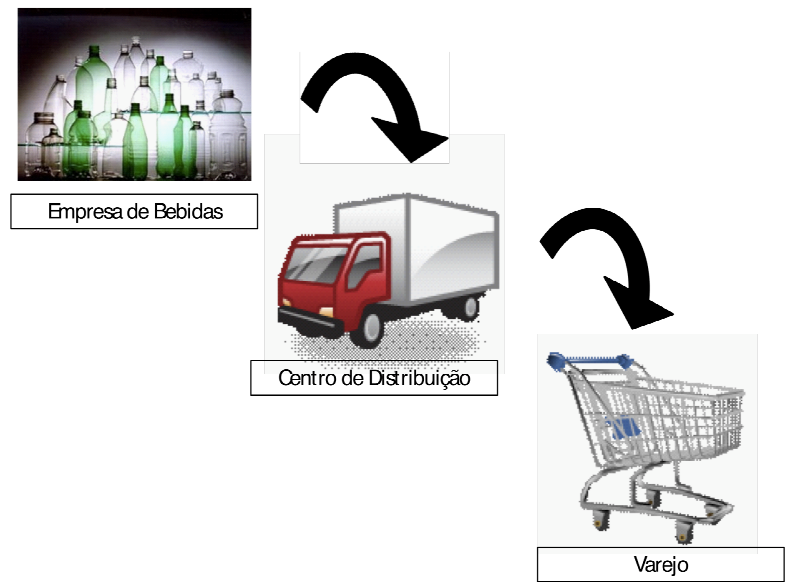

Figura 1 - Parte da cadeia de suprimentos em análise no estudo de caso

\subsection{Coleta e Análise dos Dados}

Neste estudo foram utilizados dados primários e secundários obtidos por meio de entrevistas, realizadas com os profissionais responsáveis pela previsão da demanda e os responsáveis pelos ajustes semanais. As observações diretas às diferentes atividades da empresa permitiram o acompanhamento dos dados, bem como uma percepção mais detalhada e segura dos objetos da pesquisa. Segundo Selltiz, Wrightsman e Cook (1987), a técnica de entrevista é uma situação em que se desenvolve a interação social para obtenção de informações, sendo mais adequada para a revelação de assuntos complexos, emocionalmente carregados ou para verificar os sentimentos subjacentes à determinada opinião apresentada.

Após a conclusão das entrevistas, os dados foram analisados, inicialmente, de forma individual e, posteriormente, na forma de análises comparativas entre os produtos estudados. Para tal, foi utilizada a análise de conteúdo, na qual foi possível se fazer a codificação, categorização e quantificação dos dados coletados. Essa técnica permite a abordagem das informações com a determinação de um código qualitativo para sua classificação e tratamento. Houve a preocupação de se analisar a situação de cada variável, nos momentos anteriores e posteriores à utilização da TI como suporte ao ajuste da previsão da demanda. 
Como no estudo de caso são mais evidentes os benefícios da disponibilização da informação em tempo real, optou-se por mostrar, além de momentos em que os ajustes colaboraram para a empresa, pontos em que eles não funcionaram. $\mathrm{O}$ objetivo é evidenciar o impacto negativo das falhas e destacar a necessidade de que os ajustes sejam realizados.

\section{APRESENTAÇÃO E DISCUSSÃO DO CASO}

\subsection{A empresa}

A empresa de bebidas carbonatadas está localizada na região nordeste do estado de São Paulo. Ela atua no segmento de bebidas há mais de 60 anos, estando entre as 500 melhores e maiores empresas brasileiras. Conta com um portfólio diversificado, com mais de 100 produtos, e atende mais de 300 cidades de São Paulo e sul de Minas Gerais. O faturamento mensal gira em torno de 55 milhões de reais e o volume de expedição médio mensal é de 3,5 milhões de caixas. Segundo dados da pesquisa Nielsen divulgados pela empresa, em fevereiro de 2009, ela tinha uma participação de $66,6 \%$ do mercado de bebidas carbonatadas da região atendida, contra $13 \%$ do principal concorrente e $20 \%$ de outras companhias menores somadas.

\subsection{O modelo de previsão de vendas}

A previsão de vendas na empresa é realizada em etapas, de forma que os processos qualitativos sejam complementares aos quantitativos. A matriz da empresa realiza a projeção das metas que são base para o cenário nacional dos próximos cinco anos. Desta forma, são determinadas algumas ações e estratégias que serão operacionalizadas localmente. Tais informações tornam-se mais acuradas à medida que são especificadas na previsão anual realizada pela franquia regional. 
A previsão anual utiliza dados de pesquisas econômicas, além de informações de lançamento de novos produtos concorrentes e próprios para realização da projeção do cenário que a organização está inserida. Tal projeção é feita sem a utilização de gráficos e modelos estatísticos, o que torna importante a análise qualitativa e a percepção de mercado. Esse cálculo de vendas é a base que é compartilhada com toda a cadeia, para que os fornecedores possam se programar para atender uma demanda média da empresa. Aspecto importante, visto que os fornecedores, por sua vez, também precisam comunicar suas redes de abastecimento.

Num segundo momento, essa previsão anual é desdobrada em previsões mensais, que fazem uso, principalmente, dos dados de estoque do mês anterior, histórico de vendas de cinco anos e ruptura. Como ferramenta operacional é utilizado o software de previsão, comercialmente conhecido como Forecast Pro, que é alimentado pelos dados históricos e utiliza técnicas estatísticas, tais como média móvel, ponderada e exponencial, baseadas em modelos de séries temporais. O software determina o modelo mais adequado e projeta três volumes de previsão, de acordo com um cenário pessimista, um mediano e um otimista. Tais cálculos são realizados para cada produto individualmente e por área comercial ou distribuidor, sendo que a empresa conta com um portfólio de 220 produtos, 6 áreas comerciais e 3 distribuidores.

Esta previsão é muito importante para o planejamento estratégico e, principalmente, operacional da empresa, uma vez que é a base para o cálculo da produção e da necessidade de materiais a curto prazo. Além disso, a previsão também auxilia no posicionamento estratégico pois, a partir dela, é que são definidas as ações e planejamentos de longos ou médios períodos de tempo.

As projeções geradas são encaminhadas para a avaliação do gerente de cada área comercial ou distribuidora, e estes podem contribuir de forma qualitativa, a partir de sua experiência. Os gerentes modificam a previsão de acordo com informações a respeito da concorrência, lançamentos, canibalização, descontinuidade de produto, entre outras. Além disso, os gestores têm acesso a informações de perspectivas econômicas e financeiras determinadas por empresa do setor. As alterações são avaliadas pela alta administração e a previsão mensal é formalizada e divulgada. 


\subsection{O ajuste ao modelo de previsão de vendas}

No curto prazo, existe a necessidade de um planejamento mais refinado, pois o mesmo serve de base para o MPS (Master Planning Schedule). A dificuldade existe principalmente em função deste segmento de mercado estar sujeito a constantes ajustes em função do impacto dos fatores ambientais sobre o mesmo. Chuva, frio, jogos de futebol transmitidos pela TV, entre outros, influenciam no consumo e podem afetar os estoques a curto prazo, levando a possíveis rupturas. Mesmo assim, a empresa deve estar apta a reagir a tais mudanças ou a ações mercadológicas da concorrência, na maior agilidade possível. Para isso, a empresa precisa da informação em tempo real, que é a base para a realização de ajustes à previsão tradicional de vendas.

Logo, a empresa realiza um ajuste semanal da previsão de vendas, fato importante para que ela possa redimensionar sua capacidade, sua demanda e seus recursos, para atender a real necessidade de mercado e às eventuais exigências deste segmento de negócio.

Historicamente, os ajustes são realizados desde 2002 e utilizam, como base de informações para seu funcionamento, dados qualitativos provenientes das diversas áreas da empresa, que informam possíveis motivos de divergências entre o volume planejado e o realizado. Além disso, os ajustes também utilizam informações provenientes das políticas definidas pela empresa, como estratégias, lançamentos de produtos, reposicionamentos de preços, entre outras. Um contribuinte no resultado, e que é considerado no ajuste, é o fator climático, uma vez que a temperatura e o clima ao longo dos dias influenciam o comportamento do consumidor final. Tal informação é obtida por meio de consultas a sites específicos, que preveem as condições climáticas para a semana. Além disso, são consideradas as informações de vendas do final de semana anterior, como também há uma especulação sobre a semana seguinte. Isso deve-se às possíveis variações de consumo e necessidade de reabastecimento. Para tanto, são utilizadas informações da ação da concorrência, importantes para a determinação de reações por parte da empresa; e também considera-se as ações de marketing da própria organização, que determinam as neces- 
sidades de adequações das políticas anteriormente planejadas. Existe um software desenvolvido internamente pela empresa que também auxilia nesse processo, contribuindo com a análise de informações históricas de vendas.

No entanto, o indicador mais importante na formulação dos ajustes é a disponibilidade da informação do consumo, em tempo real, de todos os pontos de venda da região nordeste do estado de São Paulo. Esta informação é obtida por meio de coletores portáteis que os representantes de venda utilizam e que informam a demanda de cada estabelecimento comercial. Desta forma, é possível executar o replanejamento semanal da produção (que é feito nas quintas-feiras) baseado, principalmente, nesta informação que é coletada ao longo do final de semana antecedente. Sendo assim, o volume de produção da semana é ajustado conforme o volume atual de estoque que é subtraído do replanejamento das vendas. Caso não fosse disponibilizada esta informação teríamos uma previsão menos precisa e, consequentemente, um aumento na ruptura e no nível dos estoques.

As informações referentes a cenário competitivo e ajustes qualitativos são provenientes principalmente da comunicação diária entre o responsável pela previsão e os gerentes das áreas comerciais. Também são consolidadas informações em uma reunião mensal formal da gerência comercial, na qual se avalia o desempenho histórico, os impactos das mudanças no cenário competitivo e é realizado o planejamento das estratégias futuras.

As previsões das 8 semanas seguintes são reavaliadas todas as quintasfeiras, ao tratar de produtos próprios, e todas as sextas-feiras, quando consideramse os produtos revendidos. O software estatístico ainda não é utilizado para a reavaliação das previsões semanais. No entanto, no momento do estudo de caso (agosto de 2010), a empresa tem um projeto em andamento para implantação desta prática.

Ainda é importante destacar que, devido às peculiaridades desse setor, não existe uma maior precisão da informação de compra do consumidor final, mas somente os dados de reposição dos estoques no atacadista. As possíveis oscilações destes estoques não podem ser muito bem mensuradas, pois a reposição não representa o real consumo final, visto que pode existir acúmulo de produtos, tanto em posse do varejista como do consumidor. 
A figura 2 representa esquematicamente o processo de previsão da demanda de maneira completa, desde a projeção a longo prazo até os ajustes semanais.

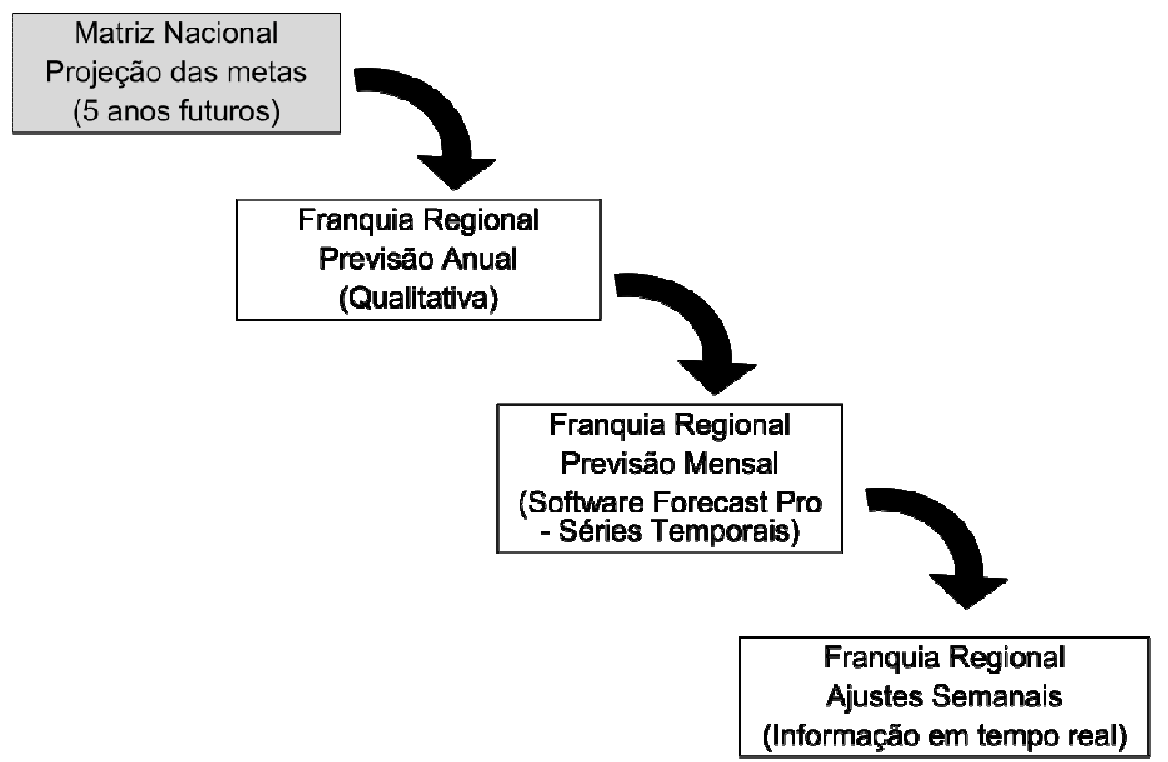

Figura 2 - Processo de previsão da demanda no longo, médio e curto prazo e processo de ajuste semanal

\subsection{Exemplos de produtos que sofreram ajustes no modelo de previsão de vendas tradicional}

Nesta seção é apresentado o estudo de caso, em um segmento da cadeia de suprimentos, da empresa investigada, relacionando alguns produtos, com o objetivo de exemplificar o ajuste da previsão mensal de vendas. Como os pesquisadores não obtiveram autorização para divulgação do nome da empresa e de seus produtos, aqui eles apresentam nomes fictícios.

No desenvolver do caso, será possível perceber a importância dos ajustes. Para cada produto, foram comparados dados da previsão original (tradicional), da previsão modificada pelos ajustes e das vendas que de fato ocorreram.

Percebe-se, por meio da análise gráfica, que o ajuste é um importante processo para se estudar em um mercado tão sazonal e instável. A figura 3 ilustra a importância dos ajustes da previsão. Ela se refere ao produto $A$, que teve seu volume 
de vendas reduzido em função do lançamento de um produto similar $B$, pela mesma empresa, em março de 2007.

Como pode ser observado, a realização dos ajustes contribuiu para evitar maiores impactos negativos relativos à mudança na demanda dentro do que foi planejado pela matriz. Logo, a empresa se adaptou a um nível menor de vendas, reduzindo a produção e evitando os possíveis estoques que seriam gerados.

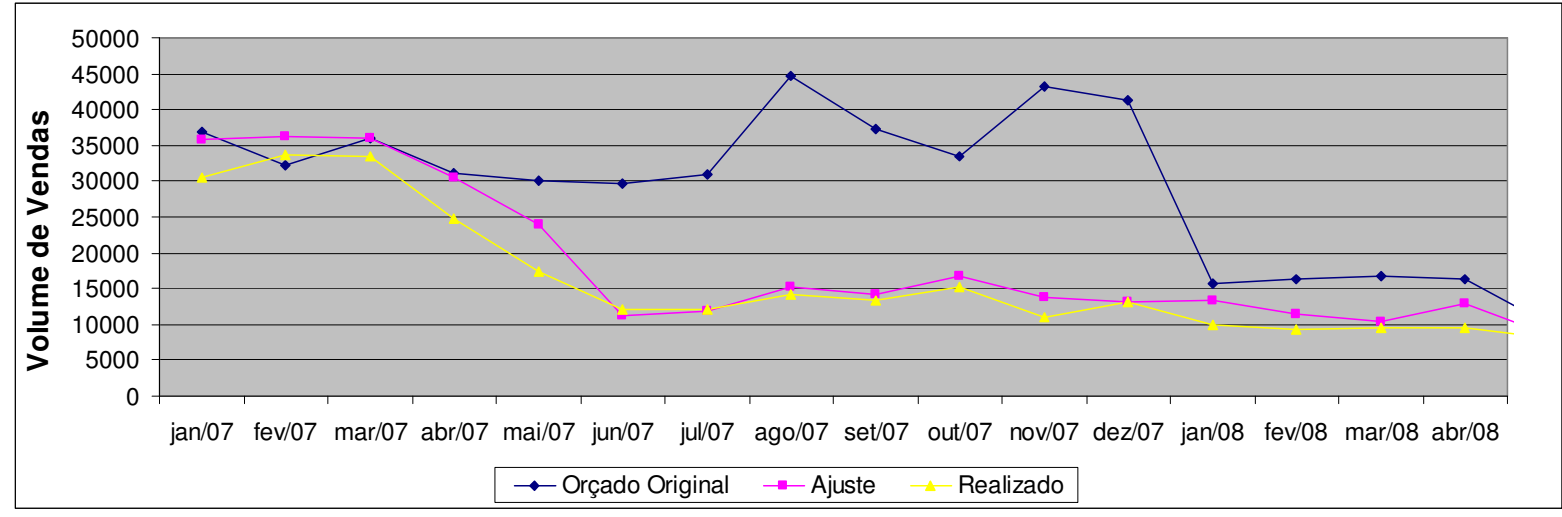

Figura 3 - Comparação entre a previsão, o ajuste e o realizado para vendas do produto A. Fonte: Fornecido pela empresa.

A figura 4, referente ao produto $C$, ilustra a importância dos ajustes à medida que destaca um momento no qual o mesmo "falhou". A partir de abril de 2008, é possível observar que foi sugerido um aumento na produção (maior do que o previsto) e, no entanto, as vendas foram menores que o esperado, o que impactou no aumento do nível dos estoques de produtos acabados. Isso influenciou no aumento dos custos com estoques. Vale destacar que em todos os outros meses do ano o ajuste colaborou na equalização dos estoques deste produto. 


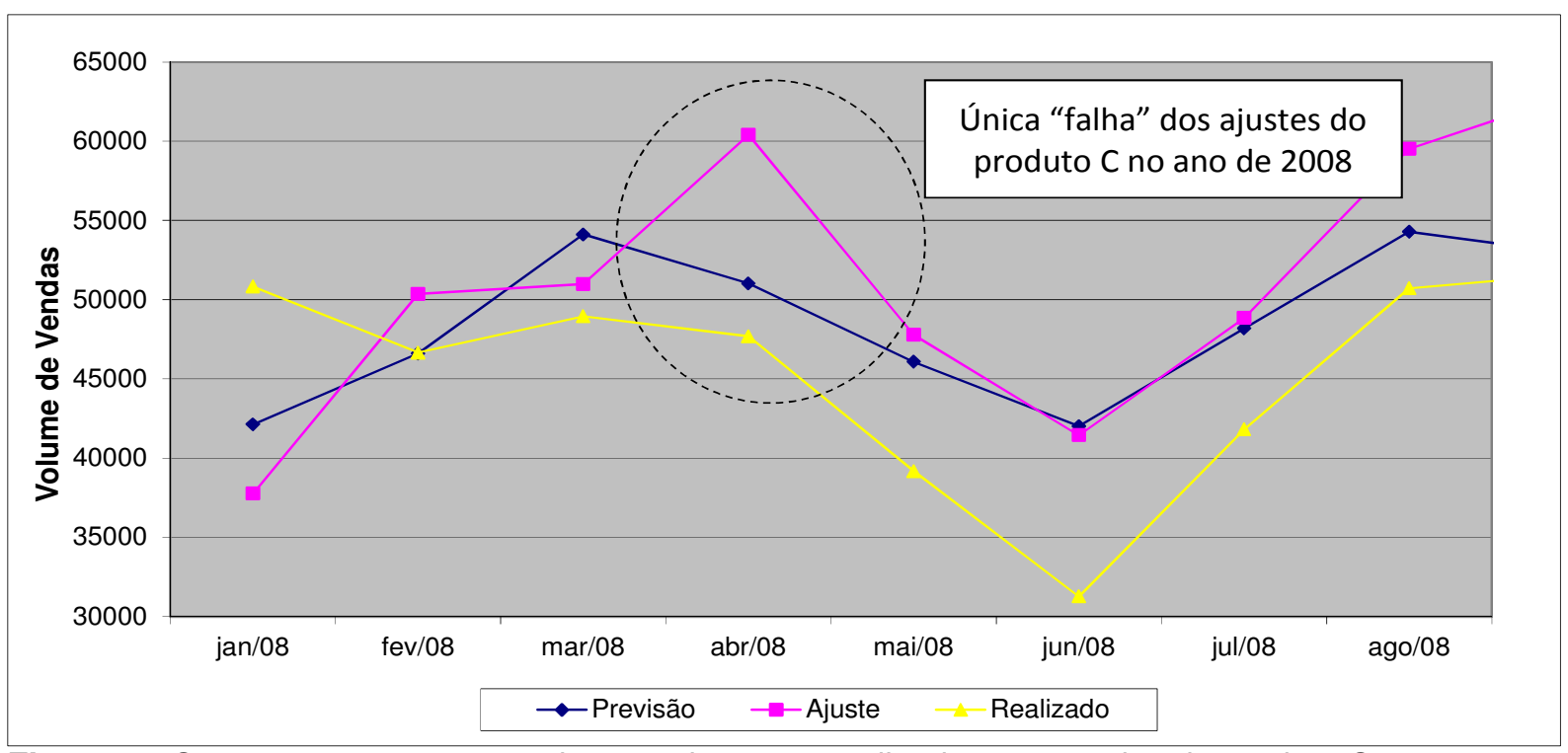

Figura 4 - Comparação entre a previsão, o ajuste e o realizado para vendas do produto C. Fonte: Fornecido pela empresa.

Os impactos negativos possíveis de serem evitados pela realização dos ajustes podem ser percebidos na situação ilustrada pela figura 5. Ela também se refere ao produto $\mathrm{C}$, enfatizando a comparação semanal entre os ajustes e o realizado. Nas duas primeiras semanas do mês de março de 2009, representadas pelas semanas 19 e 20 no gráfico, o realizado foi muito maior do que o ajuste, ocorrendo ruptura de 232 caixas do produto na semana 19, e 4.171 caixas na semana 20. Nas duas semanas seguintes ocorreu o inverso, pois o ajuste foi feito com base nas altas vendas das semanas anteriores e, sendo um fato pontual, o realizado foi muito abaixo. Nos demais meses de 2009 o ajuste foi benéfico, conforme demonstra a Figura 5.

Em relação à matéria-prima, houve necessidade de empréstimo de 25 kits de concentrado do produto $\mathrm{C}$ de outra franquia, quantidade que seria suficiente para produção de 25.000 caixas, já que o lead time do fornecedor para reposição dessa matéria-prima é de 25 dias. Além disso, foi necessário um frete especial para a busca de tampas no fornecedor, devido ao lead time desse material ser de 10 dias. Ocorreu, também, a mudança no sequenciamento da produção, priorizando o produto $\mathrm{C}$ em detrimento de outro, o que levou a uma ruptura de 2.909 caixas de um produto D. 
Um fator responsável pela mudança na demanda, influenciando o aumento de vendas nas duas primeiras semanas do mês, foi o fator climático. Foram registradas temperaturas próximas dos $40^{\circ} \mathrm{C}$, com ausência de nuvens e ventos da camada polar. Estas, foram apontadas pela mídia como as semanas mais quentes dos últimos 66 anos na região nordeste do estado de São Paulo. Segundo a responsável pelo ajuste, o aumento da temperatura afeta muito a demanda por bebidas carbonatadas do sabor do produto $\mathrm{C}$.

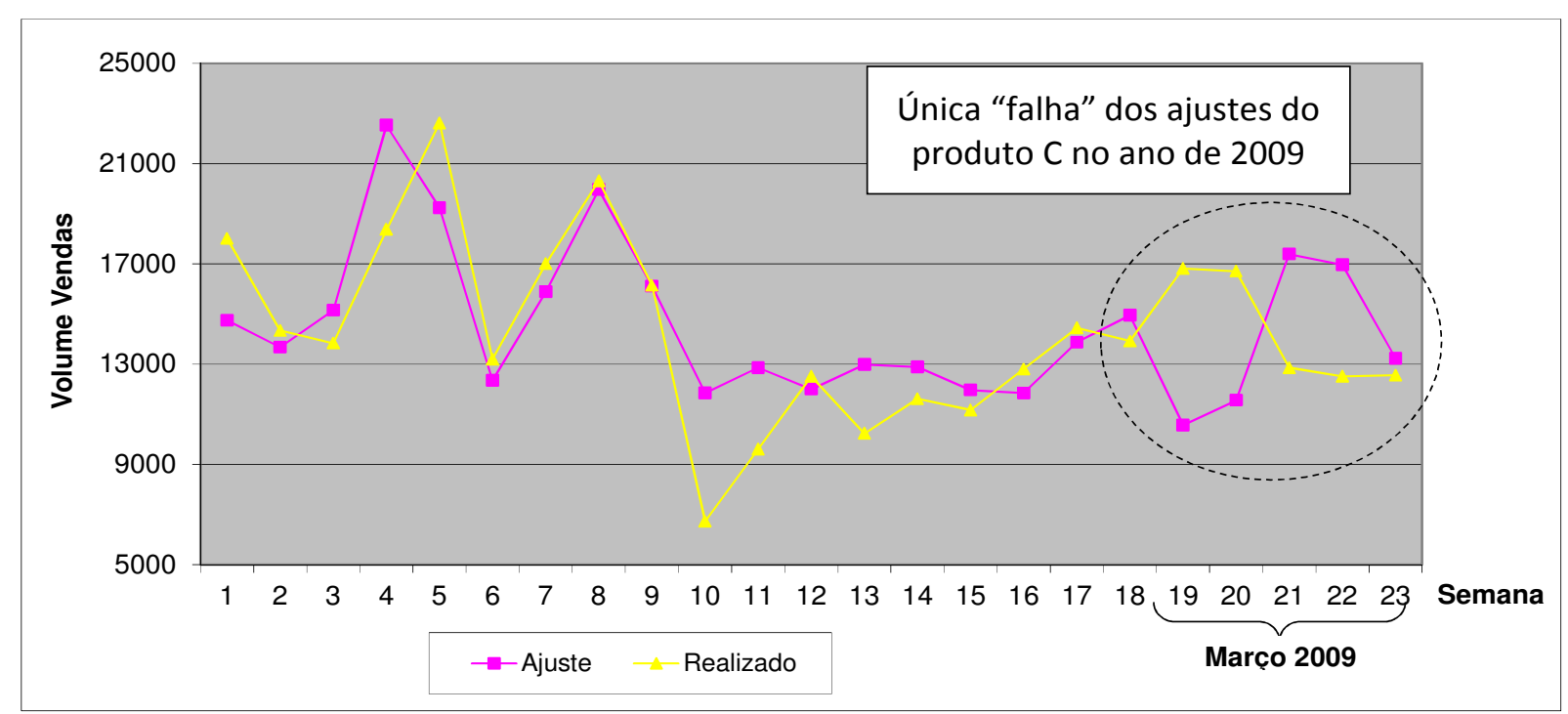

Figura 5 - Comparação semanal entre o ajuste e o realizado para vendas do produto C. Fonte: Fornecido pela empresa.

A figura 6 indica os dias em que houve ruptura no produto C. A ausência deste produto no mercado pode influenciar no nível de fidelidade dos clientes, uma vez que, ao deixar de receber o produto, os consumidores podem adquirir produtos similares de concorrentes. Isso pode implicar numa redução da participação de mercado da empresa.

O nível de ruptura neste mês para o produto $C$ superou o nível médio mensal de todos os produtos em 2008 que foi de $0,82 \%$. Na segunda semana de março de 2009 , estes valores foram de $19,98 \%$, e na terceira semana, $6,38 \%$. 


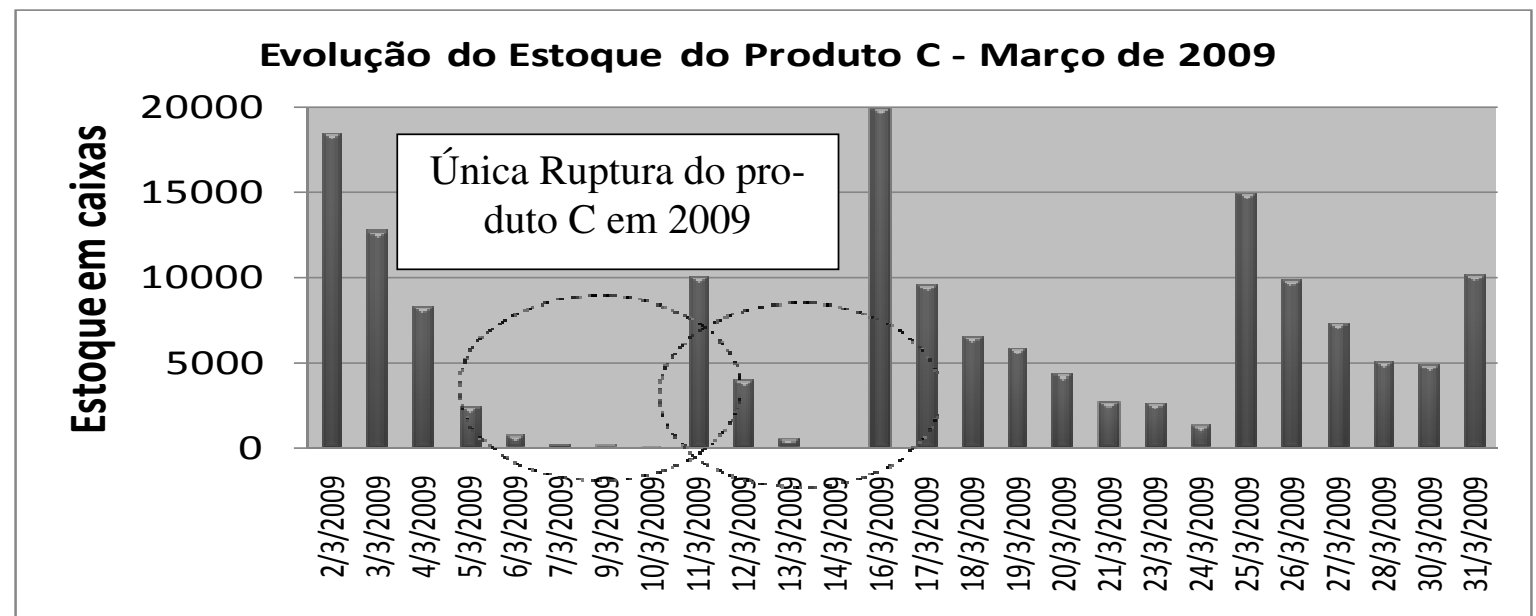

Figura 6 - Redução nos níveis de estoque do produto C.

Fonte: Fornecido pela empresa.

A figura 7 representa as vendas de todos os produtos, em março de 2009, em relação à capacidade logística da empresa. Pode-se observar que em alguns dias, especialmente no dia 9, as vendas superaram a capacidade de distribuição da empresa. Dessa forma, um replanejamento mais eficaz poderia evitar que a empresa operasse acima de sua capacidade e ocorresse um aumento nos custos logísticos.

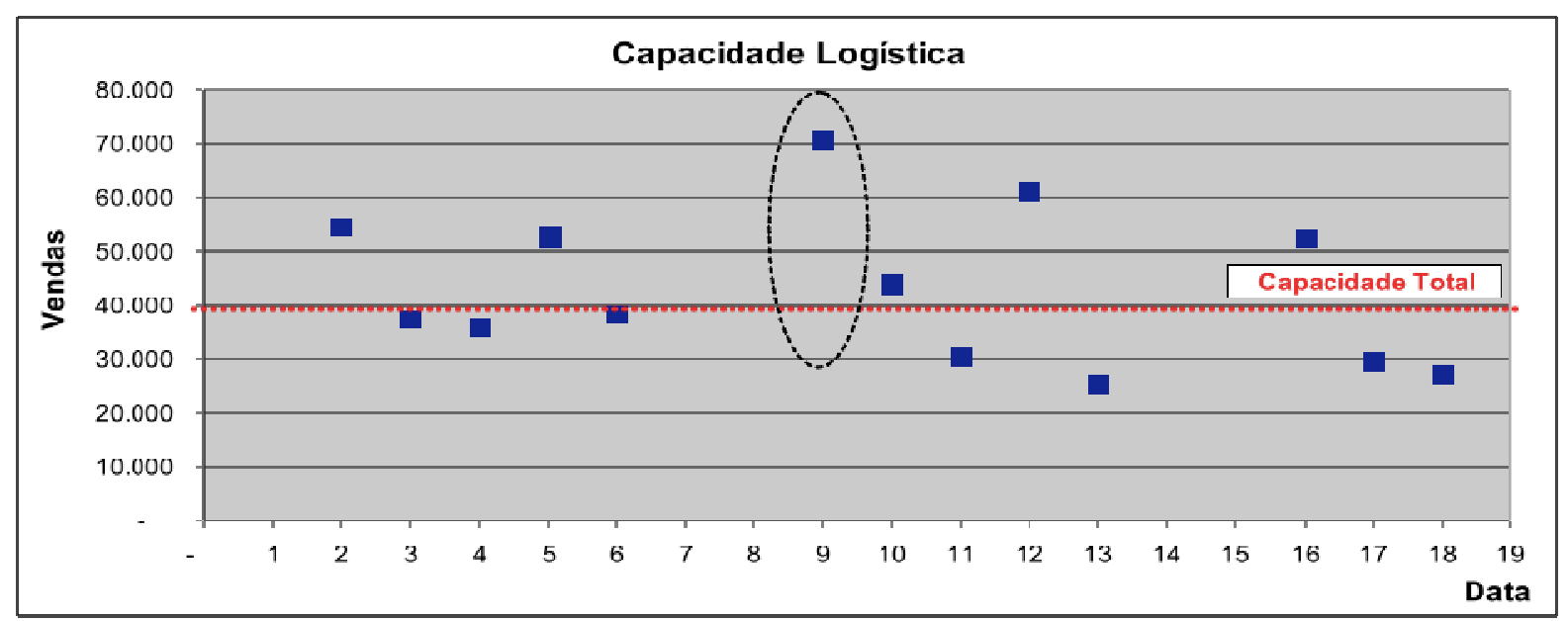

Figura 7 - Vendas de todos os produtos versus capacidade logística no mês de março de 2009. Fonte: Fornecido pela empresa.

Devido às altas vendas e à falta de previsões mais precisas, principalmente no dia 9 de março, houve a necessidade de entregas adicionais no mesmo dia. Isso é prejudicial, pois pode gerar horas extras e os caminhões circulam muito abaixo de sua capacidade total de carregamento, o que gera maiores custos unitários. A figura 
8 ilustra o aumento no número de recargas devido às vendas excessivas e não esperadas do dia 9. Como a política da empresa é a de entregar os pedidos em até 24 horas após a venda, nesta figura pode ser observado o aumento da recarga a partir do dia 10. Nos dias seguintes, os valores apresentados são maiores do que a média mensal, que foi de 8,69 .

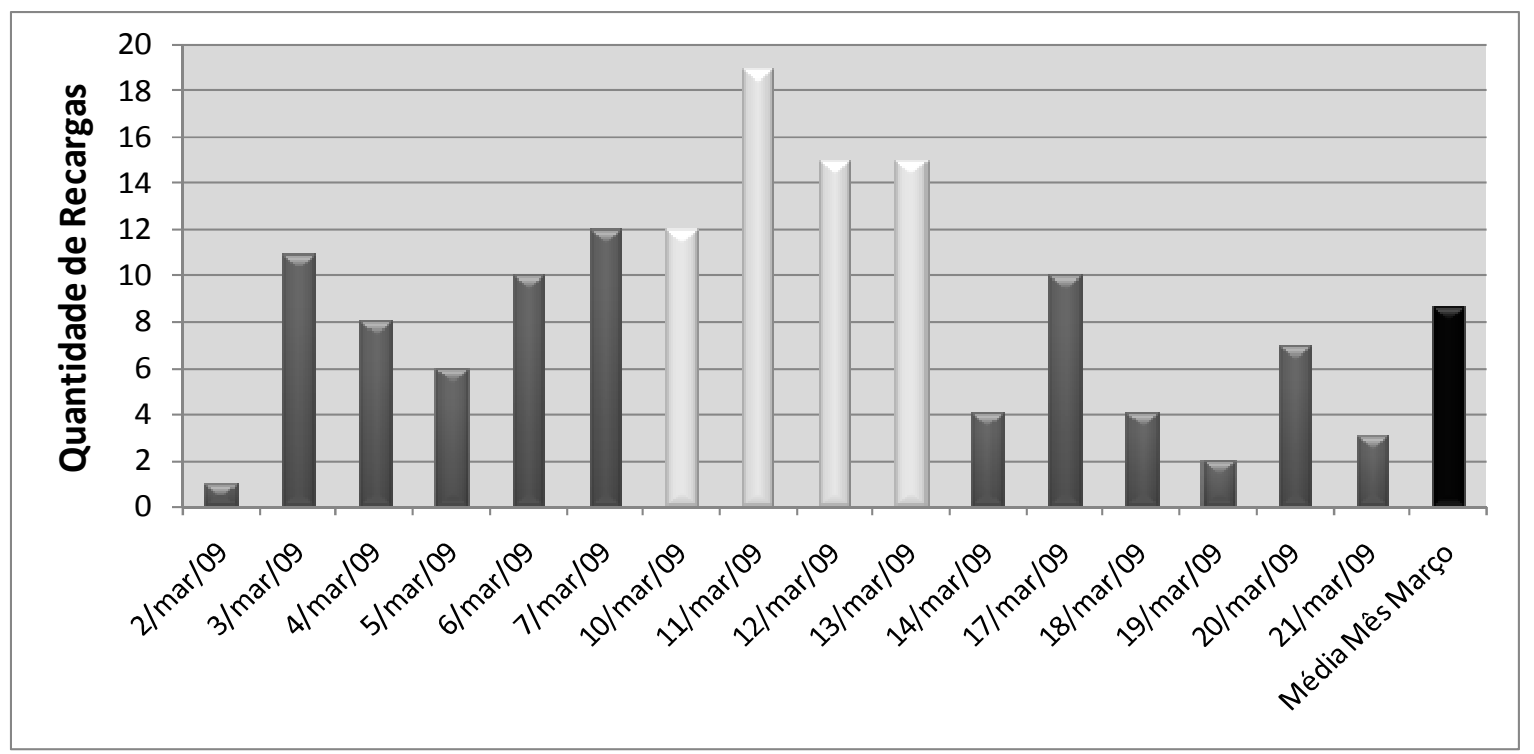

Figura 8 - Quantidade de recargas realizadas no mês de março de 2009.

Fonte: Fornecido pela empresa.

Outra consequência das altas vendas do dia 9 de março foi o aumento nos custos com comissões, horas extras e combustível, índices que podem ser observados na figura 9. Os caminhões foram desviados das rotas e transitaram com capacidade inferior à máxima, o que impactou na ineficiência operacional do sistema logístico da companhia. 


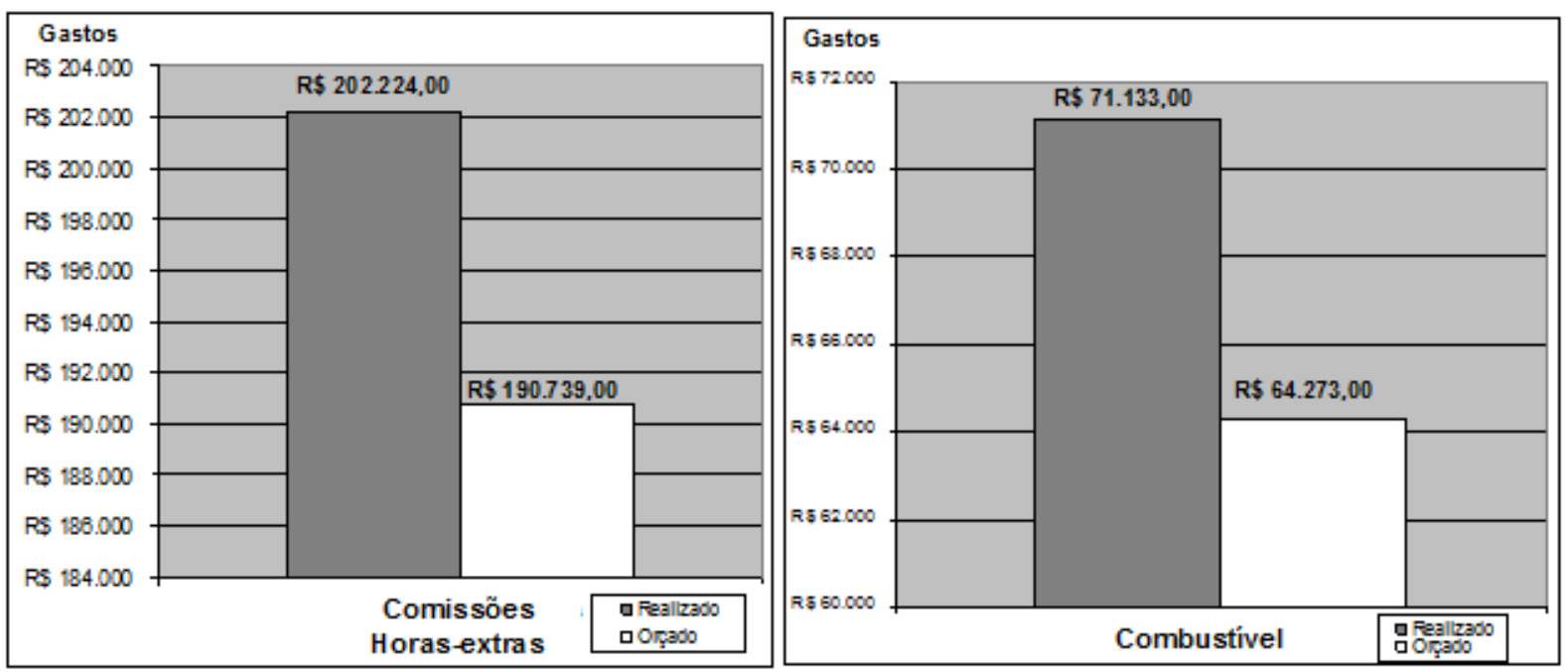

Figura 9 - Realizado e orçado dos gastos com comissões e horas-extras e combustíveis em março de 2009.

Fonte: Fornecido pela empresa.

A figura 10 representa a evolução nos níveis de estoque do produto $\mathrm{E}$, que representa $70 \%$ das vendas totais da empresa, de 2004 a 2008. Este é um indicador importante, tendo em vista que, a partir de 2003, podem ser mensurados os maiores benefícios da integração da empresa com seus fornecedores e clientes, por meio da informação em tempo real. Comparando-se sempre com o ano de 2004, pode ser observada a redução dos estoques do produto que foi, em média, de 39,09\%. Desta forma, existem indícios que ajudam a observar certa tendência de que a utilização da informação em tempo real, pode ter colaborado para redução destes estoques. Isso fica mais claro quando entende-se que os maiores impactos do processo de ajuste da previsão, por meio da TI, podem ser mensurados a partir de 2004.

Desta forma, a partir de 2004, os estoques passaram a ser atualizados, em tempo real, e os fornecedores informados mais rapidamente a respeito da reposição dos estoques de insumos básicos. Vale ressaltar que muitos departamentos estiveram envolvidos no processo, inclusive destaca-se a importância do conceito de "Iogística integrada" utilizado pela empresa. Anteriormente a 2004 a empresa não apresenta muitos dados disponíveis, mas os estoques sempre foram superiores aos praticados após 2004. 


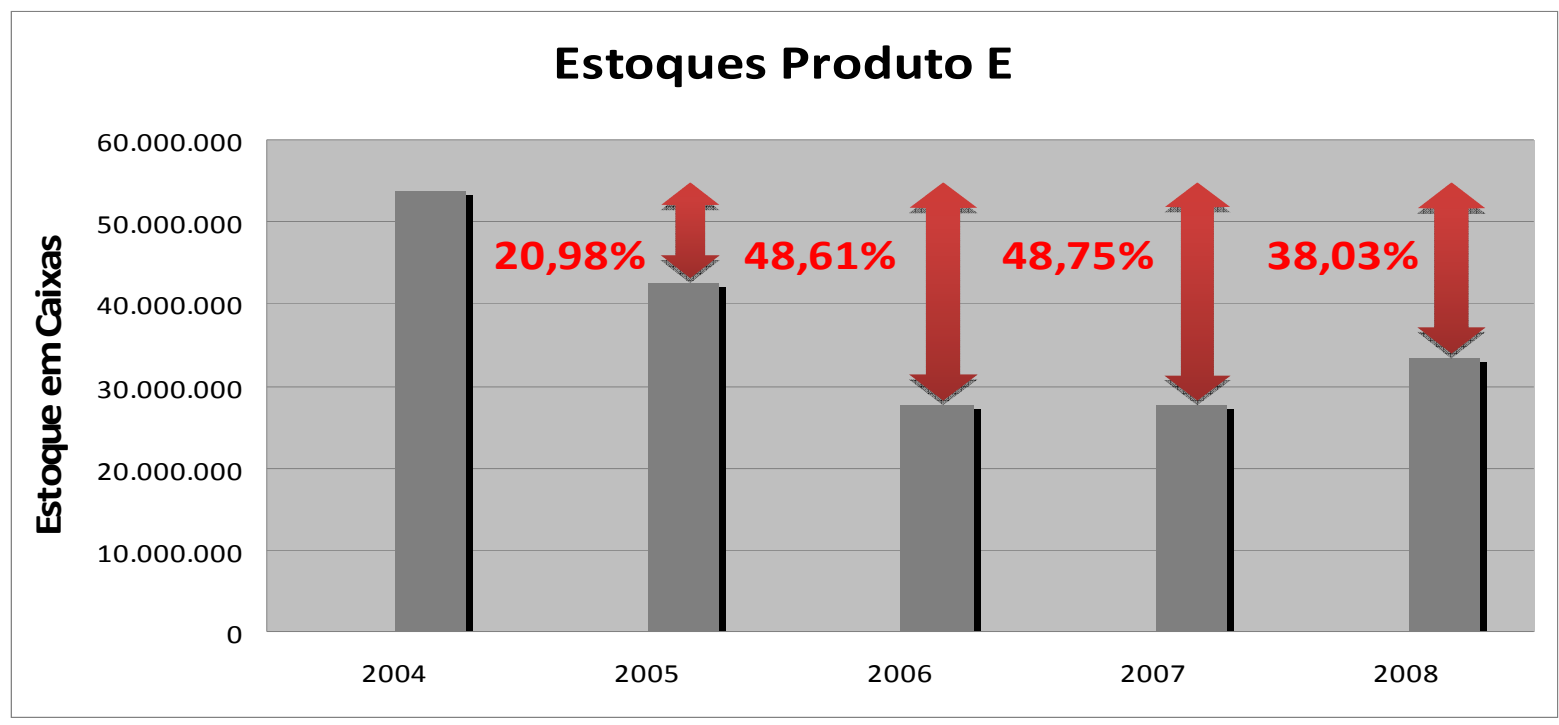

Figura 10 - Redução dos estoques do produto E.

Fonte: Fornecido pela empresa.

O quadro 2 resume os principais dados observados no estudo de caso.

\begin{tabular}{|c|c|c|}
\hline Produto & Referência & Descrição \\
\hline Produto A & Figura 3 & Importância do ajuste nos modelos tradicionais de previsão de vendas da empresa \\
\hline Produto C & Figura 4 & Única "falha" dos ajustes do produto C no ano de 2008 \\
\hline Produto C & Figura 5 & Única "falha" dos ajustes do produto C no ano de 2009 \\
\hline Produto C & Figura 6 & Única ruptura do produto C em 2009 \\
\hline Todos os produtos & Figura 7 & Demanda que excede a capacidade logística \\
\hline Todos os produtos & Figura 8 & Recarga gerada pela demanda que excede a capacidade logística \\
\hline Todos os produtos & Figura 9 & Gastos excessivos de combustível e horas-extras em função do excesso de recargas \\
\hline Produto $\mathrm{E}$ & Figura 10 & Redução nos estoques a partir de 2004 \\
\hline
\end{tabular}

Quadro 2- Quadro resumo do estudo de caso na empresa de bebidas carbonatadas.

\section{CONCLUSÕES}

Esta pesquisa teve como objetivo analisar como a informação em tempo real pode ajudar o segmento de bebidas a ajustar seu modelo tradicional de previsão de vendas.

Foram observados indícios de que, isoladamente, os modelos tradicionais, baseados em séries temporais, não contribuíram para que a empresa em estudo atingisse o nível de serviço desejado. Isso se deve ao fato de que projeções baseadas somente em dados históricos de vendas não são suficientes para prever cenários futuros nos quais essa empresa encontra-se inserida. Aspecto observado na figura 3. Sendo assim, dados revelaram uma forte tendência de que a disponibilidade 
da informação do consumo em tempo real pode ajudar a empresa a ajustar sua previsão. Como se conclui nas figuras 3 , 4 e 5.

A empresa de bebidas carbonatadas realiza a previsão de demanda tradicional utilizando o modelo de séries temporais, através do software estatístico ForecastPro. Com relação às técnicas qualitativas e quantitativas para a previsão da demanda, constatou-se que os intervalos entre as previsões, não possibilitavam que os ajustes na produção, logística e estocagem atingissem a velocidade imposta pelos novos modelos de negócio. A partir de então, identificou-se a necessidade pela adequação das previsões, em intervalos cada vez menores, o que só seria possível após a disposição da informação da oscilação das vendas em tempo real.

Segundo Arnold (1999, p. 235), "as previsões são mais precisas para períodos curtos. O futuro próximo impõe menos incertezas que o futuro distante". No estudo foi possível verificar indícios de que a empresa pode fazer previsões mais realistas e sincronizar os primeiros elos da cadeia (empresa, centro de distribuição e varejista), pois passou a disponibilizar a informação, em tempo real, do comportamento de consumo dos pontos de atacado, por meio da TI.

De acordo com Yan (2010), um benefício significativo da partilha de informações é que ela (por exemplo, pela informação da demanda do consumidor, pelas tendências de vendas e dados, etc.) melhora a precisão das informações e o planejamento da distribuição.

Dessa forma, o ajuste na previsão funciona como suplemento ao modelo tradicional de previsão da demanda. Este ajuste é baseado em dados qualitativos provenientes das diversas áreas da empresa, dados da previsão climática através de sites especializados, estratégias corporativas e informações históricas de vendas. Além disso, são utilizadas informações da ação da concorrência e ações de marketing da própria organização.

Conforme observado na figura 4, os ajustes evitam maiores impactos negativos para a empresa em situações nas quais existem mudanças na demanda que vão contra ao estabelecido no modelo de previsão tradicional. As figuras 5 e 6 ilustram casos em que o ajuste poderia ter evitado consequências negativas. É impor- 
tante observar que a falha na previsão a partir dos ajustes ocorre esporadicamente, não sendo recorrente em outros meses ao longo do ano.

Como já foi mencionado, outro problema é que o constante crescimento da oscilação da demanda de um número cada vez maior de produtos aumenta, na mesma proporção, a necessidade por reprogramação da produção. Conforme a figura 5 , a oscilação da demanda pelo produto $C$ causou reprogramação da produção, e consequente falta do produto $\mathrm{D}$.

Na figura 6, houve aumento do nível de ruptura acima da média mensal, consequência das altas vendas do produto $C$ no período. A figura 7 representa as vendas acima da capacidade logística da empresa, gerando a necessidade de entregas adicionais. Esse aumento no número de recargas pode ser observado na figura 8 . Por sua vez, o aumento na necessidade de recargas gera maiores gastos com comissões, horas extras e combustível, representados na figura 9.

A figura 10 mostra a redução média nos níveis de estoque do produto $\mathrm{E}$, que representa $70 \%$ das vendas, após a utilização do ajuste. Houve redução média de $39,09 \%$ dos estoques, o que otimiza os gastos da empresa, ressaltando a importância da disponibilização da informação em tempo real como suplemento ao modelo de previsão tradicional da demanda.

E, finalmente, por se tratar de um estudo de caso, estes dados não podem ser generalizados para outras indústrias do segmento de bebidas carbonatadas. Podese, apenas, afirmar que existe uma tendência de uma constante.

\section{REFERÊNCIAS}

ARNOLD, J. R. T. Administração de materiais. São Paulo: Atlas, 1999.

BALLOU, R. H. Gerenciamento da cadeia de suprimentos: planejamento, organização e logística empresarial. 4. ed. Porto Alegre: Bookman, 2001.

BAYRAKTAR, E.; KOH, S. C. L.; SARI, K. \& TATOGLU, E. The role of forecasting on bullwhip effect for E-BUSINESS applications. International Journal of Production Economics, v. 113, p. 193-204, 2008. 
BOSE, I.; RAKTIM, P. \& ALEX, Y. ERP and SCM systems integration: The case of a valve manufacturer in China. Information \& Management, v. 45, p. 233-241, jun. 2008.

CHANG, I-C.; HWANG, Hsin-G.; LIAW, Hsueh-C.; CHEN, Sing-L. \& YEN, D. C. $A$ neural network evaluation model for ERP performance from SCM perspective to enhance enterprise competitive advantage. Expert Systems with Applications, v. 35, p. 1809-1816, 2008.

CHEN, K. \& XIAO, T. Demand disruption and coordination of the supply chain with a dominant retailer. European Journal of Operational Research, v. 197, p. 225-234, 2009.

CHING, H. Y. Gestão de estoques na cadeia de logística integrada: supply chain. São Paulo: Atlas, 1999.

CHRISTOPHER, M. Logística e gerenciamento da cadeia de abastecimento: estratégias para a redução de custos e melhoria dos serviços. São Paulo: Pioneira, 1997.

CORRÊA, H. L. \& GIANESI, I. G. N. Just in time, MRP II e OPT: um enfoque estratégico. São Paulo: Atlas, 1996.

CORRÊA, H. L.; GIANESI, I. G. N. \& CAON, M. Planejamento, programação e controle da produção MRPII e ERP: conceitos, uso e implantação. São Paulo: Atlas, 2001.

FERNANDES, A. Tecnologia: aquisição, desenvolvimento, proteção, transferência e comercialização. Rio de Janeiro: Quadratim, 2001.

FERREIRA, D.; MORABITO, R. \& RANGEL, S. Solution approaches for the soft drink integrated production lot sizing and scheduling problem. European Journal of Operational Research, v. 196, p. 697-706, 2009.

FREITAS, L. Metodologia para avaliação e implantação de uma camada de conhecimento baseada em prototipagem em empresas que possuam sistemas de ERP. 2001. Dissertação (Mestrado em Engenharia de Produção) - Universidade Federal de Santa Catarina. Florianópolis, 2001.

GOLES, T.; HAWK, S. \& KAISER, K. M. Information technology workforce skills: The software and IT services provider perspective. Information Systems Frontiers, v.10, n.2, 2008.

GUNASEKARAN, A. \& NGAI, E.W.T. Modeling and analysis of build-to-order supply chains. European Journal of Operational Research, v. 195, p. 319-334, jun., 2009. 
HENDRICKS, K. B.; SINGHAL, V. R. \& STRATMAN, J. K. The impact of enterprise systems on corporate performance: A study of ERP, SCM, and CRM system implementations. Journal of Operations Management, v. 25, p. 65-82, jan. 2007.

KAYNAK, H. \& HARTLEY, J. L. A replication and extension of quality management into the supply chain. Journal of Operations Management, v.26, p. 468-489, 2008.

KEARNS, G. \& SABHERWAL, R. Strategic Alignment Between Business and Information Technology: A Knowledge-Based View of Behaviors, Outcome, and Consequences. Journal of Management Information Systems, v.23, n.3, 2007.

$\mathrm{KOH}, \mathrm{A}$. \& GUNASEKARAN, D. R. ERP II: The involvement, benefits and impediments of collaborative information sharing. International Journal of Production Economics, v. 113, p. 245-268, may, 2008.

MALHOTRA, N. K. Pesquisa de marketing: uma orientação aplicada. 3. ed. Porto Alegre: Bookman, 2001.

MATTAR, F. N. Pesquisa de marketing: metodologia, planejamento. 6. ed. São Paulo: Atlas, 2005.

PORTER, M. E. Vantagem competitiva: criando e sustentando um desempenho superior. Rio de janeiro: Campus, 1996.

SELLTIZ, C.; WRIGHTSMAN, L. S. \& COOK, S. W. Métodos de pesquisa nas relações sociais. São Paulo: EPU, 1987.

SILVA NETO, M. C. A utilização do ERP como ferramenta de geração de vantagens competitivas na cadeia de valor: um estudo de caso numa empresa siderúrgica. 2002. Dissertação (Mestrado em Economia) - Faculdade de Ciências Econômicas da Universidade Federal de Minas Gerais, Belo Horizonte, 2002.

SLACK, N.; CHAMBERS; S. \& JOHNSTON; R. Administração da produção. 2. ed. São Paulo: Atlas, 2002.

SOUZA, C. A. \& SACCOL, A. Z. (org). Sistemas ERP no Brasil: teoria e casos. São Paulo: Atlas, 2003.

SOROOR, J.; TAROKH, M. J. \& SHEMSHADI, A. Initiating a state of the art system for real-time SCM coordination. European Journal of Operational Research, $v$. 196, p. 635-650, jul., 2009.

YAN, R. Demand forecast information sharing in the competitive online and traditional retailers. Journal of Retailing and Consumer Services, v. 17, Issue 5, p. 386-394, September, 2010. 
YAN, R.; GHOSE, S. Forecast information and traditional retailer performance in a dual-channel competitive market. Journal of Business Research, v. 63, Issue 1, p. 77-83January 2010.

YELLAND, P. M. Bayesian forecasting of parts demand. International Journal of Forecasting, v. 26, Issue 2, p. 374-396, april/june 2010.

YIN, R. K. Estudo de caso: planejamento e métodos. 3. ed. Porto Alegre: Bookman, 2005.

WANG, M.; LIU, J.; WANG, H.; CHEUNG, W. K. \& XIE, X. On-demand e-supply chain integration: A multi-agent constraint-based approach. Expert Systems with Applications, v. 34, p. 2683-2692, 2008.

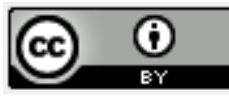

Artigo recebido em 22/06/2009 e aceito para publicação em 24/08/2010. 